\title{
Futuristic Applications for Profitable Beef Production
}

\section{Systems}

\author{
Serap Göncü, Özgül Anitaş and Gökhan Gökçe \\ Animal Science Department, Agriculture Faculty, Cukurova University, Adana 01330, Turkey
}

\begin{abstract}
The growing demands for red meats of people also present opportunities for fattening as well as improved markets for the animals. Beef production is a highly profitable venture with return of premium to the farmer. The large scale beef farming must be meet economic criteria for sustainable production. It consists of buying healthy stock, feeding and fattening them to optimum carcass weight, and selling them at any time of the year. They are handled in such a way that maximum growth is achieved at the lowest possible cost. The lifespan of operation is shorter and the return of investment is relatively higher. In beef farms which has very high genetic value of breeding animals cannot be get the expected performance without the use of technology and automation systems. Beef herd management programs if can be used as effectively, farming will have many advantages for consumer, farmer and also animals. However, to obtain these advantages from this system, required to have knowledge of the functions and effective use of the functions. The large amount of data in the obtained on many issues related to animals, herd management and an individual unless used in decisions about animals, ensuring the heavy data flow, record keeping or assessment will not give the expected results. In this study, it has been aiming that the examined the technologic applications at beef farms for sustainable and profitable meat production.
\end{abstract}

Key words: Automation, intensive, beef farms, herd management, profitability.

\section{Introduction}

Animal product is essential for healthy life of human being. Cattle farming has very difficult problems for more productive and profitable production. For more convenient and profitable production, it's possible just adopting latest technologic developments in this area. Meat production has increased rapidly over the past 50 years using many futuristic techniques. But economic analyses showed that the fattening enterprises usually yield low returns. Production input cost and management are frequently cited as important factors affecting profit. But many factors affecting the profitability of cattle fattening enterprises are numerous, diverse and often interconnected. These factors can be summarized as disease, genetics, feed availability and quality, market and operational management. Automation helps farmers to make

Corresponding author: Serap Göncü, Ph.D., professor, research field: animal science. lower energy costs and improve worker operations by improving the comfort and animals control [1].

The introduction of automation systems has a large impact on the farm, cattle and affects all aspects of farming [2]. Many specifications such as ergonomics, new positions for workers and lower costs are expected from the automated systems. Some technologic applications operate independently, but others are systemic technologies. It means that functionality of these ones being combined with other technologies. There are many opportunities for facilities in automation systems. Automation is particularly cost effective at beef farms depending on the farm scale. Automation technologies provide many options in terms of cost and ability to control use. Improved automation systems can be installed to available systems of farms or reprogramming of farm existing systems. Automation systems can manage a variety of management decisions, identification of cattle, including feeding, barn environment, weighing, disease control, farm security and worker control. 
Also the latest technologies and advances in animal production affect the economics and profitability of the different production systems. The automation of beef farms has a critical role in facilitating the many process to effect important parts of production for competitiveness of beef farms. In this study, it has been aiming that the examined the technologic applications for beef farms for sustainable and profitable meat production is reviewed.

\section{Cattle Tracking}

Cattle traceability for beef production is vitally important for provide expected meat production limits [3]. Data recording is very critical area of animal husbandry, because it provides selection, monitoring and evaluation of all animal in the herd. All these composites are playing a critical role in successful herd management and profitability. Many governments' traceability rules imposed that cattle movement must be officially traced. All of these reasons make identification essential for beef farmers. But farmers want to uses easy, understandable and cheaper tagging system. Many types of data recording system is available on the market which is varies from simple to smart types. Many of the system have contained certain level error inside. So it is the important thing to their accuracy and reliability to get best results. Also a good record keeping system should be simple and easy to interpret, and it can be provide specific remarks which implicate important findings. EID (Electronic Identification) systems are becoming more common. RFID (Radio Frequency Identification) is the use of radio waves to get animal number from tag which equipped with an antenna within a small tag [4]. RFID use radio frequency to collect data from devices attached to the animals with a small tag. EID systems provide fast and accurate identification of animals using sophisticated data management of software's. In these systems, data entrance can be done using specific reader systems [5]. Generally, data reader scans animal electronic tag, stores data or sends to the farms automation system for further evaluation. Data reading can be done with small reader or panel reader. Panel readers are installed on gates to reading animal number automatically when they passing the gate during the standard daily routine. All electronic cattle number readers have serial port which farm software communicates with the reader [4]. This active and passive transponder is available on the market. A passive transponder is used with active sensor. Generally transponders are tiny and transmit to the systems [3]. Active transponders receive incoming signals over a range and transmit on a different band. The incoming signal called uplink while outgoing signal called downlink. Active transponders used internal power source for charging for collect cattle information. Electronic identifiers can be incorporated in tags, boluses, or pastern tags. These are generally much easier to attach to the animal and to read. Electronic identifiers must be installed properly to get right time and accurate information. Electronic identification antennae systems effected by many factors such as metal rails, motors, fluorescent lighting and electric fences. Sometimes electronic tag cannot be read from antenna because of mud, animal posture, excessive animal speed and transponder errors [6].

\subsection{Electronic Weighing}

The main purpose of cattle fattening enterprises is to make profits. Generally, cattle fattening productivity depend on the gains at the end of the fattening period. Fattening performances must be providing expectations of the profitable production limits. The monitoring the weight gain, provide feed conversion rates of the individual or groups of animals. Calculated feed conversion rates helps in determining the right marketing time end of optimum fattening period. Also make farmers avoid overfeeding the animal. Using this electronic scales make farmers set and achieve certain growth rates at expected dates. The automatic weigh shuts situated at water drinkers, 
which measures the weights of his growing and finishing animals every time they go for a drink. Other, while sustainability of the work cannot be done. Many electronic systems are available for automatically identifying and weighing animals. There are many sensors and devices combined and interpreted for maximum potential can be realized. These sensor technologies offer more specific alternatives for beef enterprises for more profitable and accurate information collect and usage possibilities. Beef farmers can maximize the efficiency using effective monitoring systems on critical period for ideal targets and to make optimum profit. Accurate weighing cattle in a certain period can be one of the main key performance indicators for beef farm efficiency. Electronic scales platform sizes and capacities vary 10-30 tones. Some electronic scale models have specific pens and gates for specific aims. For example two-end swing gates make farmers work comfortable and safely during the hard work. Also special diamond design of electronic scales floor made comfortable cattle footing surface during the weighing. There are 3 main parts of scales which are platform, load bars and indicator. The different models, different manufacturers have different prices scales parts combine as a unique system under software programs. Some scales can be used for group weighing while other used for individual weighing. Electronic weigh systems generally combined with electronic identification to prepare report to make some important decisions. Systems calculate optimum fattening period using weight gain and feed consumption and stored it for further evaluation. Electronic scales with an internal memory tabulate figures based on the history of the animal and compare current weight. All these information recorded and further evaluation can be done at personal computer for analysis and archiving. One electronic scale can weigh 40 cattle in 10 minutes. Electronic scales may be justified as a way to determine body condition score automatically.
Electronic monitoring cameras are to be installed above the weighing scales to get conformation scores too. The walk over weight technology are automatically weighed cattle on the way to the water trough and data transmitted to the office computer. Adapting auto drafting to the electronic weighing cattle can be separated automatically on the basis of farmer preferences.

\subsection{Live Animal Carcass Evaluation}

The live animal carcass characteristics can be measured using new ultrasound technology referred to as real time ultrasound. The real time ultrasound using sound display muscle and fat tissues under a live animal hide [7]. Live animal body composition can be determined some time before sending to slaughter houses, this is a very important tool for price determination early stage without slaughter [8]. Carcass evaluation is a very important stage for better beef production. Using ultrasound technology results can be obtained earlier stage, larger breeding stock and commercial producers $[9,10]$ to produce more convenient information for cattle breeding. Ultrasound technology provides clean, early and convenient noninvasive methods for meat quality detection. Ultrasound technology allows identification of animals with low fat-containing carcass, as well as the optimum rate of fat in the animal to be slaughtered. The basic principle of ultrasound is to measure the reflection of sound waves from carcass textures. Differences in ultrasound equipment and technicians can effect carcass evaluation results. For ultrasound imaging, different modes are used to examine the carcass characteristics. Carcass muscle, fat and bone ratio is very important product for some other industries. Carcass fat, bone and tissue ratios have a direct effect on dressing percentages which ultimately determine beef retail prices.

Ultrasound equipments are divided to amplitude mode, brightness mode and real-time ultrasound machines. Amplitude mode is the display of amplitude spikes of different heights depending on the time. 
Brightness mode or real-time ultrasound machines determine tissue densities using echo intensities and brightness [11]. Brightness mode display strong and weak echoes using large and small dots.

A-mode ultrasonic unit with a transducer installed a single crystal for depth readings at one point [12]. As a noninvasive substitute for the ruler probe ultrasonic equipment was used to measure fat thickness which is easy to obtain on the live animal. These measurement improve prediction capacity of ultrasounds of 12-13th rib fat and longissimus muscle area [13]. Ultrasound technicians measures on the frozen image digitally on a computer. At these stage images are usually evaluated with specific software and reported to the users [12]. Greiner, S. P. [8] analyzed 7,044 Hanwoo steers using Ultrasound Measurements of Backfat Thicknes and marbling score to estimate genetic parameters. The measurement of 12 th rib back fat, rump fat, marbling and rib eye area of live animals provide important data for carcass grading.

The scanning live animals for getting cross sectional image and capture image evaluation requires too much time and effort. Many research conduct to automatic image interpretation in order to make fast and correct image processing and minimize human error. Many attempts have been made for this purpose but results varied. Hassen, A., et al [14] reported that ultrasound measurement at age $365 \mathrm{~d}$ give accurate results comparable slaughter at age $448 \mathrm{~d}$.

\subsection{Feeding Automation}

Feeding is a very important cattle behavior for cattle fattening farms aspect of the effect on profitability. The main objective of beef enterprises is to promote DMI (Dry Matter Intake) to support daily weight gain. Beef cattle spend 1-6 hours/day eating [15]. The cattle feeding behavior show changes depending on the different feeding strategies to meet their nutritional requirements. Generally frequent feeding provoke higher feed intake and then give more production [15]. Feeding consists of providing feed sequentially to all pens requiring feed, time and quality. The good feed efficiency ability has tremendous effect on beef profitability [16]. Fresh feed on the feed bunk motivate cattle to eat more feed. Because this fresh feed has a positive influence on cattle fattening profitability, automatic feeding systems improved profitability.

Feed costs make $50-70 \%$ of the cost of production in cattle fattening farms. A feed efficiency improvement of approximately $10 \%$ will reduce feed costs as a whole operation [17]. Many factors are effective on the feeding costs. Just one side is to using cheaper food. But efficient herd feed bunk management is also necessary to keep profitability high [17].

The cattle requirements which is mainly depend on weight, body condition, age, production stage and breed and feed arability must be comparable for profitable production for each operation. The main purpose of a beef cattle feeding program is to meet the nutrient requirements of animals properly and in a balanced manner. Proper feeding systems should be selected to ensure correct and balanced feeding [18]. Advances in technology allow improved feed efficiency measurement. The feed efficiency is the meaning of feed consumption of animal for per kilogram body weight and expressed as a ratio. Feed conversion ratio can be expected $6 \mathrm{~kg}$ feed consumption of animal for 1 kilogram body weight gain is acceptable in fattening enterprises. But feed consumption cannot be determined as an individual because of difficulties to measuring.

Many innovative technologies aim to improve efficiency. Individual monitoring cattle during fattening period is very key factor for profitable production. Each animal eats at a feed bunk, which is which measure the food consumed by animals. This system automatically reads e-tags and starts collecting data about feeding detail. Collected data transferred to the computer for further economic evaluation and reporting. 
This technology also reports problem animals which reduced intakes or ill animal that need treatment. But this system required individual monitoring closely and system routinely monitoring for best results. This system reports also feeding behavior data that can sickness risk animal for clinical control [19]. Individually monitoring of feed consumption electronic ear tag was used. When the electronic tag passed into the specific feed bunk, ear tag reader captured the tag's number and report data to the computer for evaluation. But this monitoring system also required an electronic floor scale which controlled by center computer software for improved for this purpose. All these system data stored in the computer to prepare specific report which provides the feed dry matter consumption of the each animals.

There are various systems such as rail-guided feed wagons, conveyor belt system and self-propelled feeders that are driven by an electric motor [20].

These self-propelled feeders perform a number of functions including loading and mixing different ingredients. And then distribute directly the right rations on time using a built-in weighing system.

Self-propelled feeders combine both the speed and comfort of a self-propelled machine along with the efficiency and fiber preservation of a cutting system. This system provides more often feeding a day which provokes dry matter intake and improves feed efficiency. Conveyor belts are one stationary solution for feeding. The conveyor belt feeder is the combination of conveyor belt and sliding scraper for automatic feed supply systems. The above the feeding table, conveyor belt pushes the feed down for feeding [21]. In this system The feed transported to the cow using v-shaped belt. The belt length is 12 to 90 meters while belt width is 45 to 60 centimeters.

The conveyor belt automatically loaded by machines. The chain link table system is also automatic feeding for cattle which is a chain with pushers on a narrow feeding table. Automatic belt feeder is available on the market for various size farms.
Rail transportation system used many areas as in livestock farming. Many vehicles can be adapted usage for automation possibilities.

An automated rail guided feeding vehicle would travel at speeds less than $16 \mathrm{~km} / \mathrm{h}$ and carry a load that would not create a risk in case of a failure. Generally personnel cannot be around feedlots and cattle are in their pens. An automated rail guided feeding vehicle provides basic safety requirements [22]. An automated rail guided feeding vehicle has feed hopper with scale system that is suspended from a rail. A computer installed the feed hopper and all data and program controlled by this computer and software using feed data, rations, frequency of the feedings.

Driverless vehicles: the automation of feeding operations in large feedlots implies a driverless vehicle. The driverless vehicles use wires which transmit a guidance signal. The wire buried 30 to 50 $\mathrm{cm}$ below the surface. The receptors mounted on the machine pick up the signal and work for this schedule [22]. To automation of truck operation is still experimental stage for fattening farms, so commercial system is not available.

\subsection{Barn Environment Control}

Beef cattle are kept in many climatic regions which means that are exposed to many climatic conditions. All barn types aims to protect animal from climate, but other stress factors (dust, mud or gaseous, contaminants). Because of detrimental effect on animal performance which mainly provide farm profitability [2]. Beef animals such as all other farm animals can give the expected performances only if required conditions are met. Cattle need to maintain a constant body temperature $\left(38.8 \pm 0.5^{\circ} \mathrm{C}\right)$ in order to sustain body physiologic balance. Environmental factors such as temperature, humidity and air velocity, influence cattle thermal balance [23, 24]. When beef barns are planned, all these climatic environmental factors are taken into consideration and the animal's requirements are tried to be met. A cattle barn must be 
provides an optimal environment for optimum production conditions [25]. Also cattle welfare issues required optimal barn environment for high production [26, 27]. The monitoring and automation control of important environmental parameters are necessary to achieve high yield at low expense. In general, barn automation involves barn air control, humidity, illumination, roof, curtain management and barn gases control applications. The first barn environment control system consists of sensors, both inside and outside, that monitor all important environmental variables which affect cattle welfare. Many sensors developed for these purpose. Barn environment manipulated mainly using software programs and their applications with corresponding equipments.

The wireless temperature sensors can be used to track the temperature in their barn, or send an alarm in case of dangerous temperature values. The barn ventilation management is very important applications, especially, difficult periods. Spring and autumn has specific significant changes in barn microclimate. During these difficult seasons practical management applications must be considered for optimum barn microclimate. Automation systems not only can automate for temperature, but also have wind and rain sensors. The wind sensors feed wind speed data into the controller, which then adjusts curtain height to compensate for higher air transfer rates [28]. The rain sensor can be programmed to close the curtain to a predetermined height when it rains to keep moisture off cows and stalls. Another sensor application for electric voltage monitoring powered equipment in the farm. The farm doors security control sensors allow farmers keep their farm secure. Farmer get receive an alert message when a specific barn gate opened by unwanted people.

The barn environment is a microclimate for farm worker also. And barn is not only for animals but also for people working there. Because of this, the worker requirements also considered for barn environment control applications. Cattle ideal temperature 13-18 degree while worker ideal temperature 15-25 degree. Weather data is used to account for environmental effects better.

\subsection{Health Observation}

As a general concept, disease affect cattle production in many aspects. It is a reason of many economic losses in feedlots. The animal disease has serious economic impact on farm animal profitability [29]. Fighting animal diseases in many countries requires large budgets and many professions, public institutions and private groups are involved in this area. Parasites and long-acting diseases in cattle breeding are very effective in economic losses. Most important cattle disease can be summarized as follows; brucellosis, tuberculosis, foot and mouth disease, IBR, pastourella, leptospirosis. Latest wireless sensor technologies, consisting of sensors and transmission units, provide healthier livestock production. The sensor technologies have been used to early detection for health from individual cows. [30]. To detect lameness early stage, many characters assed such as gait scores, time spent lying down, steps length and cow weight distribution to their legs [31]. Lameness is prevalent in modern dairy herds and has detrimental effects on productivity and animal welfare [32]. Many researchers try to develop fully automatic and correct lameness detection system. There are many lameness detection system that is on the market, but results is variable. Van Nuffel, A., et al. [33] and Maertens, W., et al. [34] were developed automated lameness detection system without presence of an operator using position sensors. Another group researcher reported that fully automated lameness detection system using load cells (Rajkondawar, U., et al. [35], Pastell, M., et al. [36], Liu, J., et al. [37]). Another group researcher is also study about cattle lameness detection system using computer vision [38-42]. The system report lame cattle in need of treatment must be separated from the herd automatically. But this lame cow 
separation would be problem at beef farm because of inadequate barn equipment. In the future barn design can be adapted to the beef animal separation to get more profit.

Image or audience based analysis can help farmers isolate disease animal from its herd. Ill animal cough sounds are very different from the normal cow sounds which easily distinguishable from other vocalizations. The ill animal cough sound differences were used for disease detection using real time monitoring. Aerts, J. M., et al. [43], Debrezeni, L. A., et al. [44]. Ferrari, S., et al. [45] developed a real-time cough classification algorithm in order to acquire an automatic monitoring system for animals. Image analyses systems also can help farmers to determine automatically animal stress and weak animal in the herd.

The risk of SARA (Sub-acute Ruminal Acidosis) increases with high-concentrate diets usage to cattle. To early diagnosis of SARA, the wireless $\mathrm{pH}$ sensors were developed and introduced to the farmers [46, 47]. It is believed that early disease detection system in conjunction of wireless sensors can achieve prevention of diseases, and thus reduce economic losses. A wireless rumen sensor determines the $\mathrm{pH}$ level and the temperature of rumen automatically. An all recorded data are transmitted to an external receiver automatically without any wire. Rumen sensor is generally working wireless, invisible and stay lifetime of animal. This is also used for tracking of animal location, health monitoring and recovering stolen animals. SARA is a common disease in beef cattle, and is characterized by low ruminal $\mathrm{pH}$. Rumen sensors monitor rumen condition for animal health early diagnosis. The theoretical life span of sensors have over 600 days which mainly depend on transmission frequency and of battery power [48]. Monitoring rumen conditions has very important effect for cattle husbandry because a rumen problem may cause death of animals suddenly. Sato, S., et al. [49], developed bolus-type wireless sensor nodes which were inserted into the rumen using a special instrument via the cow's oral cavity. The ruminal $\mathrm{pH}$ was measured and stored every 15 minutes and this information was then transmitted wirelessly [40]. The sensor can be used continuously for a period of two to three months without replacing the battery, and can be recovered orally with special instruments. When sensor determine abnormal information transferred to the system to main computer, and automatically send report which contain warning message [48]. Sensors also compares data with the expected normal value of cow, and determines the causes of the abnormal reading [50]. Image analyses system for gait scoring another solution for SARA early detection.

\section{Results}

This paper provided a relatively detailed discussion about possible futuristic applications for profitable beef production systems to meet health food demand of human population. The various futuristic applications, different control strategies, experimental results, or new commercialized technologic applications for beef enterprises were widely discussed for better production. Beef animals such as all other farm animals can give the expected performances only if requirements and conditions are met. Cattle are homoeothermic animals and need to maintain a constant body temperature. Many environmental factors influence cattle thermal balance. It can be concluded that understanding beef cattle physiology and environmental factors together with analyzing them and use on the control parameters give more profitable production. This entire factor and their interactions with environment, engineering modeling, simulation concepts and software programs, support a more efficient and successful designing of the automation control system. Many technologic applications and solutions help achieve a better production while saving precious grower time. These solutions are designed to help farmers maximize their production, help manage their production costs and help with animal welfare issues. 


\section{References}

[1] Göncü, S., Anitaş, Ö., Güngör, C., and Gökçe, G. 2017. "New Technology Usage for Sustaniable Dairy Cow Reproductive Perfomances." Journal of Environmental Science and Engineering B 6 (2017): 370-9. doi:10.17265/2162-5263/2017.07.00.

[2] Göncü, S., and Gökçe, G., 2017. "Technologic Applications at Turkish Beef Farms for Sustainable and Profitable Meat Production." Çukurova J. Agric. Food Sci. 32: 29-34. Accessed June 14, 2017. http://dergipark.gov.tr/download/article-file/397796.

[3] Bett, B. 2016. Developing a Livestock Traceability System for Domestic and Export Markets in Pastoral Areas of Eastern Africa. ILRI Project report, Nairobi, Kenya.

[4] Doğan, H., Çağlar, M. F., Yavuz, M., and Gözel, M. A. 2016. "Use of Radio Frequency Identification Systems on Animal Monitoring." SDU International Journal of Technological Science 8 (2): 38-53.

[5] Wilson, D. W., and Beers, P. T. 2001. "Global Trade Requirements and Compliance with World Trade Organization Agreements: The Role of Tracing Animals and Animal Products." Rev. Sci. Tech. Off. Int. Epiz. 20 (2): 379-84

[6] Burns, M., Prescott, E., Scharko, P., and Wycoff, C. 2015. "Beef Cattle: Types of Identification." Livestock \& Forages. Accessed April 14, 2017. https://www.clemson.edu/extension/publications/files/liv estock-forages/lf03-beef-cattle-id.pdf.

[7] Pathak, V., Singh, V. P., and Sanjay, Y. 2011. "Ultrasound as a Modern Tool for Carcass Evaluation and Meat Processing: A Review." Int. J. Meat Sci. 1: 83-92.

[8] Greiner, S. P. 1997. "The Use of Real-time Ultrasound and Live Animal Measurements to Predict Carcass Composition in Beef Cattle.” Ph.D. Thesis. Iowa State Univ..

[9] Temple, R. S., Stonaker, H. H., Howry, D., Posakony, G., and Hazeleus, M. H. 1956. "Ultrasonic and Conductivity Methods for Estimating Fat Thickness in Live Cattle." Proc. West. Sect. Am. Soc. Anim. Prod. 7: 477.

[10] William, A. R., 2001. Live Animal Carcass Ultrasound: Can It Benefit You. USA: Mississippi State University, 2253.

[11] Stanford, K., Jones, S. D. M., and Price, M. A. 1998. "Methods of Predicting Lamb Carcass Composition: A Review." Small Rumin. Res. 29: 241-54.

[12] Stouffer, J. R., and Liu, Y. 1996. "Real Time Ultrasound Technology: Current Status and Potential." In Proceedings National Swine Improvement Federation Conference and Annual Meeting. Accessed July 4, 2001. http://www.nsif.com/conferences/1996/stouffer.htm.
[13] Greiner, S. P. 1997. "The Use of Real-time Ultrasound and Live Animal Measurements to Predict Carcass Composition in Beef Cattle." Retrospective Theses and Dissertations 11987. Accessed October, 2017. http://lib.dr.iastate.edu/rtd/11987.

[14] Hassen, A., Wilson, D. E., and Rouse, G. H. 1999. "Evaluation of Carcass, Live and Real-time Ultrasound Measures in Feedlot Cattle: II. Effects of Different Age end Points on the Accuracy of Predicting the Percentage of Retail Product, Retail Product Weight, and Hot Carcass Weight." J. Anim. Sci. 77 (2): 283-90.

[15] Belle, Z., André, G., and Pompe, J. C. A. M. 2012. "Effect of Automatic Feeding of Total Mixed Rations on the Diurnal Visiting Pattern of Dairy Cows to an Automatic Milking System.” Bio Systems Engineering 111 (1): 33-9.

[16] Bewley, J. 2010. "Precision Dairy Farming: Advanced Analysis Solutions for Future Profitability." Presented at the 1st North American Conf. on Precision Dairy Management, 2-5 March, Toronto, Canada.

[17] Lima, N. L. L., Silva Sobrinho, A. G., Almeida, F. A., Endo, V., Zeola, N. M. B. L., Almeida, A. K., et al. 2013. "Quantitative and Qualitative Characteristics of the Non-carcass Componentes and the Meat of Lambs Fed Sunflower Seeds and Vitamin E." Revista Brasileira de Zootecnia 42: 51-60.

[18] Göncü, K. S., and Gökçe, G. 2007. “Animal Welfare Issues and Critical Control Points in Dairy Cattle Farming." Hasad Journal 23: 32-7.

[19] Dahlke, G., Strohbehn, D. R., Ingle, C., and Beedle, P. 2008. "A Feed Intake Monitoring System for Cattle." Animal Industry Report 654 (1): 28.

[20] Grothmann, A., Nydegger, N., Moritz, C., and Bisaglia, C. 2017. "Automatic Feeding Systems for Dairy Cattle-Potential for Optimization in Dairy Farming." Accessed December 2017. https://pdfs.semanticscholar.org/a355/8d2875b05a2e6e1f ccf7f20b63575b3b3fc4.pdf.

[21] Bisaglia, C., Belle, Z., Van den Berg, G., and Pompe, J. C. A. M. 2018. "Automatic vs. Conventional Feeding Systems in Robotic Milking Dairy Farms: A Survey in the Netherlands." J. Dairy Sci. 91: 3372-84.

[22] Boily, R. J. 1980. Digital Control for Automating Feed Distribution in Feedlots. Iowa State University Ames, Iowa. Accessed October, 2014. https://lib.dr.iastate.edu/cgi/viewcontent.cgi?referer=https ://www.google.com.tr/\&httpsredir=1\&article $=7685 \&$ cont ext $=$ rtd.

[23] Göncü, K. S., and Özkütük, K. 2003. "Shower Effect At Summer Time On Fattening Performances Of Black And White Bullocks." Journal of Applied Animal Research 23: 123-7. 
[24] Koluman, N., and Daskiran, I. 2011. "Effects of Ventilation of the Sheep House on Heat Stress, Growth and Thyroid Hormones of Lambs." Tropical Animal Health and Production 43: 1123-7.

[25] Koluman, N., and Cankaya, S. 2008. "The Effects of Ventilation and Showering on Fattening Performances and Carcass Traits of Crossbred Kids." Small Ruminant Research 75: 192-8.

[26] Göncü S., Koluman N., Serbester U., and Görgülü M. 2013. "Animal Welfare Issues and Critical Control Points in Dairy Cattle Farming." Çukurova Agriculture Food Sciences Journal 31 (1): 9-20.

[27] Kaliber, M., Koluman, N., and Silanikove, N. 2016. "Physiological and Behavioral Basis for the Successful Adaptation of Goats to Severe Water Restriction under Hot Environmental Conditions." Animal 10: 82-8.

[28] Neethirajan, S. 2017. "Recent Advances in Wearable Sensors for Animal Health Management." Sensing and Bio-Sensing Research 12: 15-29.

[29] Dijkhuize, A., Huirne, R., and Jalvingh. A. 1995. "Economic Analysis of Animal Disease and Their Control." Preventative Veterinary Medicine 25: 135-49.

[30] Hogeveen, H., Kamphuis, C., Steeneveld, W., and Mollenhorst, H. 2010. "Sensors and Clinical Mastitis-The Quest for the Perfect Alert." Sensors (Basel) 10 (9): 7991-8009.

[31] Chapinal, N., de Passillé, A. M., Rushen, J., Wagner, S. A. 2010. "Effect of Analgesia during Hoof Trimming on Gait, Weight Distribution, and Activity of Dairy Cattle." J. Dairy Sci. 93 (7): 3039-46. doi:10.3168/jds.2009-2987.

[32] Edwards, J. 2018. "The Importance of Livestock Identification and Movement Control to the Promotion of Anımal Disease Control and Facilitation of Trade." Accesssed January, 2017. https://www.oie.int/doc/ged/D682.PDF.

[33] Van Nuffel, A., Vangeyte, J., Mertens, K. C., Pluym, L., De Campeneere, S., Saeys, W., et al.2013. "Exploration of Measurement Variation of Gait Variables for Early Lameness Detection in Cattle Using the GAITWISE." Livestock Sci. $\quad$ 156: 88-95. doi:10.1016/j.livsci.2013.06.013.

[34] Maertens, W., Vangeyte, J., Baert, J., Jantuan, A., Mertens, K. C., De Campeneere, S., et al. 2011. "Development of a Real Time Cow Gait Tracking and Analysing Tool to Assess Lameness Using a Pressure Sensitive Walkway: The GAITWISE System.” Biosyst. Eng. 110: 29-39. doi: 10.1016/j.biosystemseng.

[35] Rajkondawar, U., Lefcourt, A. M., Neerchal, N. K., Dyer, R. M., Varner, M. A., Erez, B., et al. 2002. "The Development of an Objective Lameness Scoring System for Dairy Herds: Pilot Study." Trans. ASABE 45: 1123-5. doi: $10.13031 / 2013.9941$.
[36] Pastell, M., Hänninen, L., de Passillé, A. M., and Rushen, J. 2010. "Measures of Weight Distribution of Dairy Cows to Detect Lameness and the Presence of Hoof Lesions." $J$. Dairy Sci. 93 (3): 954-60.

[37] Liu, J., Dyer, R. M., Neerchal, N. K., Tasch, U., and Rajkondawar, P. G. 2011. "Diversity in the Magnitude of Hind Limb Unloading Occurs with Similar Forms of Lameness in Dairy Cows." J. Dairy Res. 78 (2): 168-77.

[38] Poursaberi, A., Bahr, C., Pluk, A., Van Nuffel, A., and Berckmans, D. 2010. "Real-time Automatic Lameness Detection based on Back Posture Extraction in Dairy Cattle: Shape Analysis of Cow with Image Processing Techniques." Comput. Electr. Agric. 74: 110-119. doi: 10.1016/j.compag.

[39] Thorup, V. M., Nascimento, O. F., Skjøth, F., Voigt, M., Rasmussen, M. D., Bennedsgaard, T. W., et al. 2014. "Short Communication: Changes in Gait Symmetry in Healthy and Lame Dairy Cows based on 3-Dimensional Ground Reaction Force Curves Following Claw Trimming." J. Dairy Sci. 97 (12): 7679-84.

[40] Blackie, N., Bleach, E., Amory, J., and Scaife, J. 2013. "Association between Locomotion Score and Kinematic Measures in Dairy Cows with a Varying Hoof Lesion Type." J. Dairy Sci. 96: 3564-72. doi:10.3168/jds.2012-5597.

[41] Viazzi, S., Bahr, C., Schlageter-Tello, A., Van Hertem, T., Romanini, C. E., Pluk, A., et al. 2013. "Analysis of Individual Classification of Lameness Using Automatic Measurement of Back Posture in Dairy Cattle.” J. Dairy Sci. 96 (1): 257-66.

[42] Van Hertem, T., Viazzi, S., Steensels, M., Maltz, E., Antler, A., Alchanatis, V., et al. 2014. "Automatic Lameness Detection based on Consecutive 3D-Video Recordings." Biosyst. Eng. 119: 108-16. doi:10.1016/j.biosystemseng.

[43] Aerts, J. M., Jans, P., and Halloy, D. 2005. "Labelling of Cough Data from Pigs for On-line Disease Monitoring by Sound Analysis." Transaction of the ASAE 48 (1): 351-4.

[44] Debrezeni, L. A., Korpáš, J., and Salát, D. 1990. "Spectra of the Voluntary First Cough Sounds." Acta Physiologica Hungarica 75 (1990): 117-31.

[45] Ferrari, S., Silva, M., Guarino, M., Aerts, J. M., and Berckmans, D. 2008. "Cough Sound Analysis to Identify Respiratory Infection in Pigs." Computers and Electronics in Agriculture 64 (2): 318-25.

[46] Neubauer, V., Humer, E., Kröger, I., and Zebeli, Q. 2017. 2017. "Differences between $\mathrm{pH}$ of Indwelling Sensors and the $\mathrm{pH}$ of Fluid and Solid Phase in the Rumen of Dairy Cows Fed Varying Concentrate Levels." J. Anim. Physiol. A. Anim. Nutr. 102 (1): 10.

[47] Sato, S., Mizuguchi, H., Ito, K., Ikuta, K., Kimura, A., 
and Okada, K. 2012. "Technical Note: Development and Testing of a Radio Transmission $\mathrm{pH}$ Measurement System for Continuous Monitoring of Ruminal $\mathrm{pH}$ in Cows." Prev. Vet. Med. 103: 274-9.

[48] Nogami, H., Arai, S., Okada, H., Zhan, L., and Itoh, T. 2017. "Minimized Bolus-Type Wireless Sensor Node with a Built-In Three-Axis Acceleration Meter for Monitoring a Cow's Rumen Conditions.” Sensors 17 (4): 687. doi:10.3390/s17040687.
[49] Sato, S., Kimura, A., Anan, T., Yamagishi, N., Okada, K., Mizuguchi, H., and Ito, K. 2012. "A Radio Transmission $\mathrm{pH}$ Measurement System for Continuous Evaluation of Fluid pH in the Rumen of Cows." Vet. Res. Commun. 36: 85-9.

[50] Nogami, H., Okada, H., Miyamoto, T., Maeda, R., and Itoh, T. 2013. "Wearable and Compact Wireless Sensor Nodes for Measuring in Temperature of the Base of a Calf's Tail." Sens. Mater. 25: 577-82. 